\title{
WAVE OGIVES
}

\author{
By E. D. WADDINGTON
}

(Department of Geophysics and Astronomy, University of British Columbia, Vancouver, British Columbia V6T 1W5, Canada)

ABstract. Wave ogives arise in a solution of the continuity equation by the method of characteristics. Steady ice flow is assumed. Ice velocity, channel width, and mass-balance functions combine to form a wave-excitation potential that yields the forcing function for wave ogives. This linear-systems formulation extends the ogive theory of Nye. Convolution of the temporal cumulative mass balance and spatial forcing functions gives the total wave pattern below an ice fall. Many ice falls do not generate ogives because the wave amplitude is modulated by a factor related to ice-fall length. The wave ogives at Austerdalsbreen, Norway, are due almost entirely to ice acceleration at the top of the ice-fall, i.e. the same zone that King and Lewis showed was responsible for forming Forbes bands.

RÉsumé. Ogives de vague. Des ogives de vagues apparaissent comme solution de l'équation de continuité par la méthode des caractéristiques, en supposant un écoulement permanent. La vitesse de la glace, la largeur du courant et le bilan de masse s'ajustent pour former un potentiel d'excitation de vagues qui détermine la fonction de forçage des ogives de vague. Cette formulation de systèmes linéaires, développe la théorie des ogives de Nye. Une convolution du bilan accumulé au cours du temps allié à une fonction de forçage donne le comportement total d'une vague à la suite d'une chute de glace. Beaucoup de chutes de glace ne

\section{INTRODUCTION}

Ogives are transverse surface features that form at the rate of one per year at ice falls on some alpine glaciers. Ogives travel down-glacier at the surface velocity of the ice, so that the wavelength of an ogive pattern is the distance ice flows in one year. There are two related types of ogives: pairs of alternating light and coloured bands, called "Forbes bands", first described by Forbes (1843), and topographic waves called "wave ogives". Not all wave trains on glaciers are wave ogives. Trains of serac blocks formed in ice falls can cause wave patterns down-stream (Tyndall, 1874 , p. 180; Washburn, 1935; Fisher, 1947; Sharp, 1960; Vallon, unpublished), and compressive stress gradients can cause wave trains distinct from wave ogives (Holdsworth, 1969; Hughes, 1971, 1975; Williams, 1979). Ogives occur in many parts of the world, e.g. the Alps (Forbes, 1843), Norway (King and Lewis, 1961), Iceland (Ives and King, 1954; King and Ives, 1956), Greenland (Atherton, 1963), the Canadian Rockies (Sherzer, 1907, p. 50), the Andes (Lliboutry, 1957, 1958), the Karakoram (Yafeng and Wenying, 1980), the Himalaya (Haefeli, 1957), and Alaska (Leighton, 1951).

King and Lewis (1961) described the origins of the coloured bands. In their view, crevasses near the top of Odinsbreen ice fall on Austerdalsbreen, Norway, collect dust in summer and snow in winter. Years later, when these closed and compressed crevasses are below the ice fall, they

*Present address: Graduate Program in Geophysics AK-50, University of Washington, Seattle, Washington 98195, U.S.A. donnent pas naissance à des ogives parce que l'amplitude des vagues est modulée par un facteur lié à la longueur de la chute de glace. Les ogives de vague de l'Austerdalsbreen, Norvège, sont pratiquement entièremement dues à l'accélération de la glace au sommet de la chute, c'est-à-dire la même zone que King et Lewis ont trouvée responsable de la formation des bandes de Forbes.

Zusammenfassung. Wellen-Ogiven. Wellen-Ogiven treten in einer Lösung der Kontinuitätsgleichung mit der Methode der Charakteristiken auf. Es wird stetiger Eisfluss angenommen. Funktionen der Eisgeschwindigkeit, der Kanalweite und der Massenbilanz ergeben kombiniert ein Potential der Wellenerregung, das die Erzeugungsfunktion für WellenOgiven darstellt. Diese Formulierung in linearen Systemen erweitert die Ogiven-Theorie von Nye. Die Konvolution der zeitlich kumulierten Massenbilanz und der răumlichen Zwangsfunktionen liefert das vollstăndige Wellenmuster unter einem Eisbruch. Viele Eisbrüche erzeugen keine Ogiven, weil die Wellenamplitude durch einen Faktor, der von der Länge des Eisbruchs abhängt, moduliert wird. Die WellenOgiven am Austerdalsbreen in Norwegen stammen fast ganz von der Beschleunigung des Eises am Beginn des Eisbruchs, also derselben Zone, die nach King und Lewis für die Bildung von Forbes-Bändern verantwortlich ist.

are seen as narrow structural bands $(1-100 \mathrm{~cm}$ thick) of dirty and bubbly ice, respectively, extending to a large depth in the glacier. The Forbes bands are the result of variations in the numbers of these narrow structural bands per unit distance down the glacier. Leighton (1951), Lliboutry (1957), Fisher (1951, 1962), Vallon (unpublished), Reynaud (1979), and Lliboutry and Reynaud (1981) discussed the foliated structure of ogives. The view that the banded structure is sedimentary in origin (Agassiz, 1840, p. 40; Vareschi, 1942; Fisher, 1947; Godwin, 1949) is now largely discredited.

It has long been known that there is some connection between wave ogives and Forbes bands. Tyndall (1874, p. 131 ) and King and Lewis (1961) associated the dark bands with the troughs of the wave ogives and the light bands with the crests. Atherton (1963) and Elliston (1957), who worked in a variety of different climatic regions, associated the dark bands with the leading slopes of the waves.

Typical wave ogives may have a crest-to-trough amplitude of $10 \mathrm{~m}$ right below the ice fall. The amplitude usually decays with distance travelled down the glacier, so that of ten only $10-20$ waves are seen. Differential mass balance due to snow drifts in the troughs (Nye, 1958; Lick, 1970) and, possibly, viscous relaxation of the waves (Glen, 1958; Vallon, unpublished) reduce the wave amplitude. these processes usually dominate the wave amplification caused by longitudinal compression down-glacier from the ice fall. Some wave-ogive trains persist, however, for many more years, e.g. Trimble Glacier North Branch, Alaska Range (Fig. 1).

Early theories of ogive-wave formation (Forbes, 1843; Haefeli, 1951[a], [b], 1957; Streiff-Becker, 1952) favoured a seasonally varying longitudinal stress at the foot of the ice 


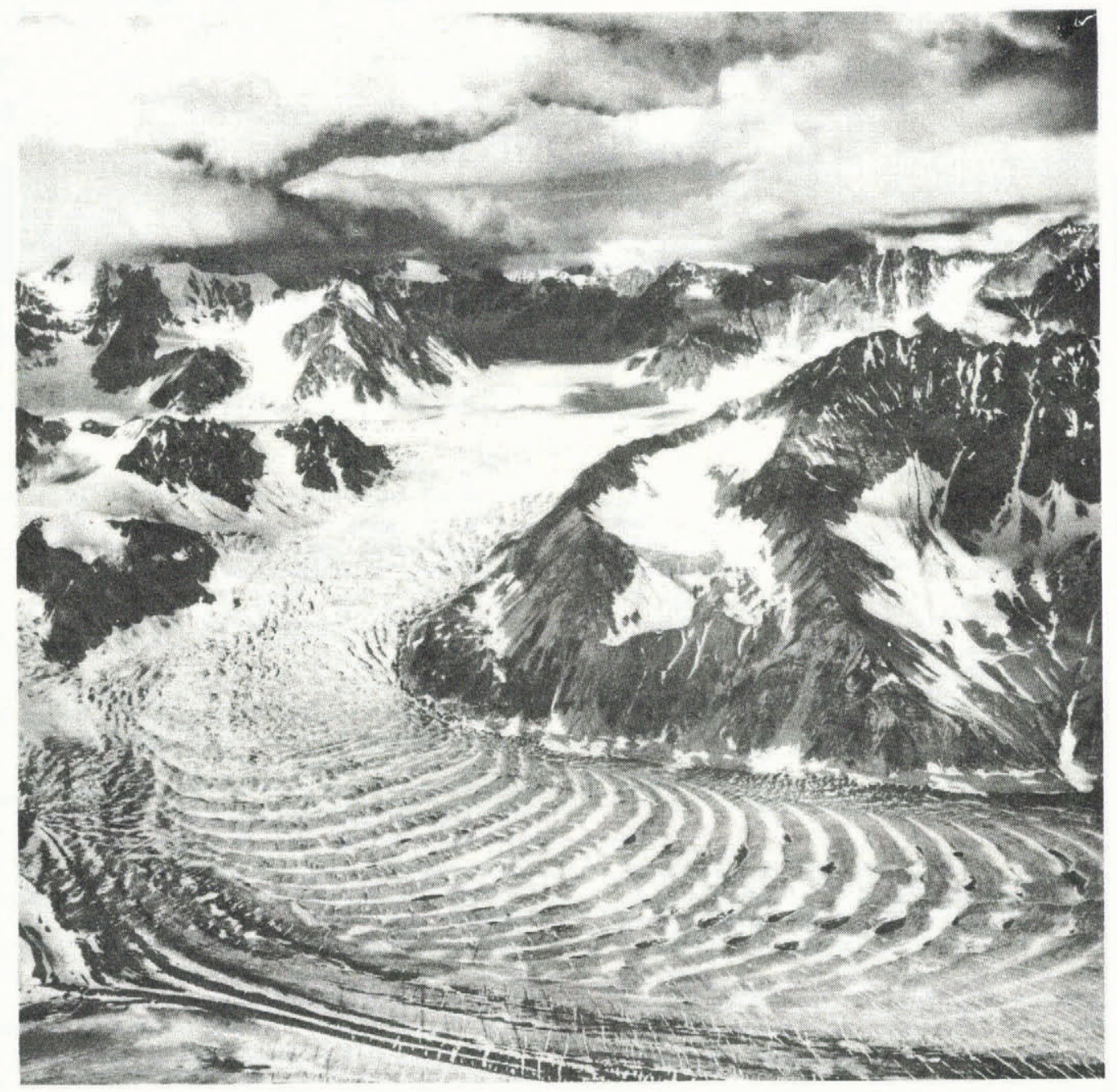

Fig. 1. Wave ogives on Trimble Glacier, Alaska. (Photograph by A.S. Post; U.S.G.S. Project Office-Glaciology negative \# F654-94.)

fall; these variations were assumed to be caused by seasonal changes in the sliding velocity. From strain observations on Austerdalsbreen, however, Nye (1959[a], [b]) calculated the distribution of stress and found that the ogives there could not be explained by seasonal pressure changes. Nye (1958) proposed another mechanism for creating wave ogives. He showed that, even when the flow was steady, annual waves should be expected below an ice fall, due to interaction between the annually periodic seasonal mass balance and the large plastic deformations taking place in the ice fall. A vertical column of ice passing through an ice fall in summer is stretched horizontally by the local high velocity gradients, thus exposing a larger surface area than ice columns of equal volume immediately above and below the ice fall. This ice in the ice fall in summer loses a larger fraction of its volume to ablation, becoming a trough in an ogive-wave train down-glacier from the ice fall. Vallon (unpublished, p. 51) applied Nye's theory to the generation of ogives from Séracs du Géant on the Mer de Glace. Martin (1977) showed that this mechanism could also generate kinematic waves at ice falls in response to fluctuations of climate. The Nye theory is the basis of the developments reported here. Washburn (1935) also suggested that the annual mass-balance cycle could cause wave ogives but he did not attempt to formulate the principle mathematically.

Large seasonal variations in velocity exist on many glaciers and these seasonal changes may well cause additional annual waves. However, to quote Nye (1958), "If the waves from an icefall are thought to be due entirely to some other process, it is then necessary to explain why the ablation mechanism is absent." Because the mechanism described by Nye is capable of generating large annual waves that adequately explain observed wave ogives, I will restrict further attention to the simple case of steady ice flow. The existence of waves caused by unsteady flow merits attention but is not examined here.

\section{QUANTITATIVE TREATMENT}

Let $x$ be the coordinate in the direction of ice flow and $U(x)$ be the forward velocity of the ice. Because the theory concerns regions of thin and rapidly sliding ice, $U(x)$ is approximately equal to the ice-surface velocity.

Since the wavelength of wave ogives where they become visible below an ice fall rapidly becomes less than the ice thickness (due to compressive flow), the wave forms are too short to propagate as kinematic waves (Langdon and Raymond, 1978) (Nye (1958) discussed this possibility), and the waves do not perturb the flow. This is consistent with the assumption that $U(x)$ is independent of time, i.e. $\partial U / \partial t=0$. The waves are simply carried forward at the velocity of the ice surface, which is treated strictly as a "conveyor belt" in this theory. Letting $h(x, t)$ be ice thickness, Nye defined an Annually Repeating State (ARS) by $h(x, t)=h(x, t+1)$ for time in years. $W(x)$ is the transverse width between two flow lines, $A(x, t)$ the massbalance rate, and $Q(x, t)$ the ice flux given by

$$
Q(x, t)=h(x, t) U(x) W(x) .
$$

Following a section of ice moving at $U(x)$ in channel of unit width, Nye used the steady-velocity assumption to convert the continuity equation

$$
\frac{\partial h(x, t)}{\partial t}+\frac{1}{W(x)} \frac{\partial Q(x, t)}{\partial x}=A(x, t)
$$


to the total derivative form

$$
D Q(x, t) / D x=A(x, t) \text {. }
$$

Odinsbreen ice fall at Austerdalsbreen is in the ablation zone. Nye assumed that the amount of winter snowfall there was unimportant to the wave-generation process, being merely a protective covering for the true glacier surface. To simplify the analysis, he also assumed that the net annual ablation of ice occurred instantaneously each year at time $t_{0}$, i.e.

$$
A(x, t)=b(x) \sum_{n=-\infty}^{\infty} \delta\left(t-t_{0}+n\right)
$$

where $\delta(t)$ is the Dirac delta function, $n$ is an integer, and $b(x)$ is the net annual balance given by

$$
b(x)=\int_{0}^{1} A(x, t) \mathrm{d} t .
$$

He then derived a recursion relation for the glacierthickness profile $h(x)$ in an ARS immediately after the ablation at $t_{0}$

$$
h(x)=\frac{U(x-\lambda)}{U(x)} h(x-\lambda)-b(x)
$$

for ice that was at position $(x-\lambda)$ one year previously. Nye assumed a constant input ice thickness of $13.8 \mathrm{~m}$ at the

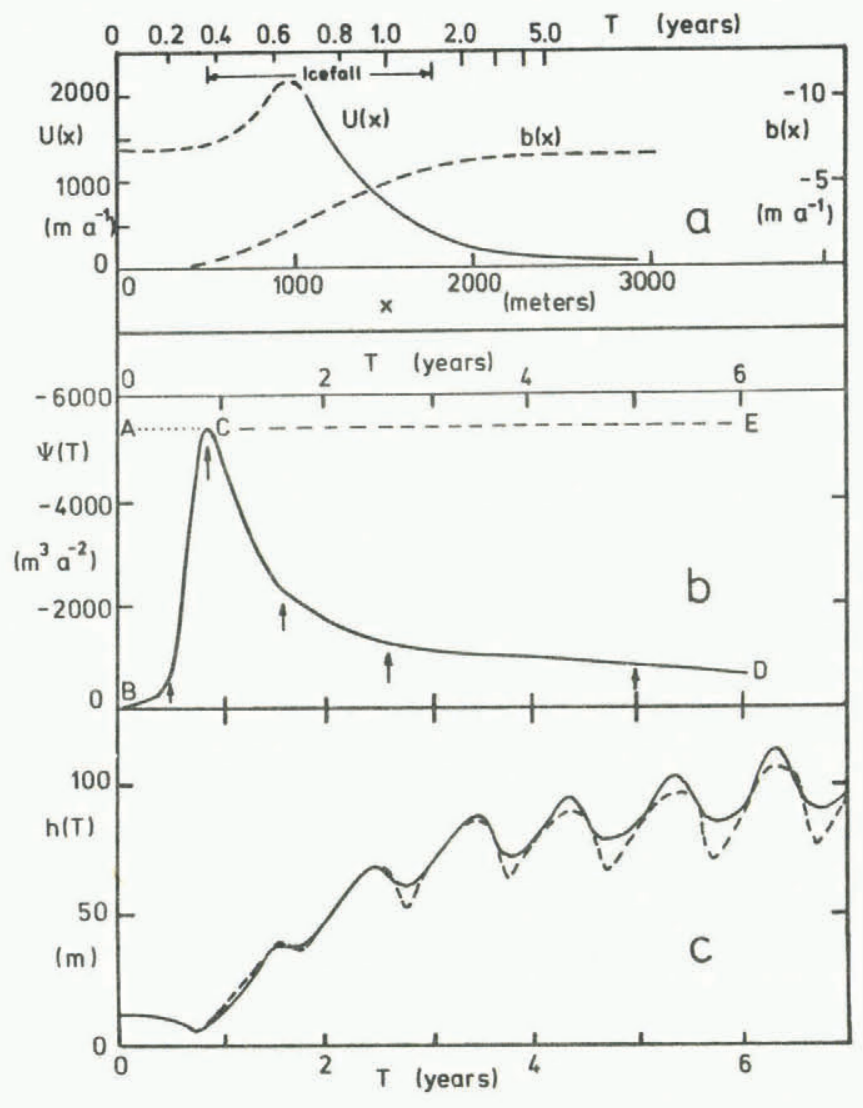

Fig. 2. (a) Austerdalsbreen velocity and mass balance. Odinsbreen ice fall; curves redrawn from Nye (1958). $T(x)$ is the time in years for ice to flow from the origin to position $x$. (b) Wave-excitation potential for $W=1 \mathrm{~m}$. Arrows indicate approximately linear sections in Table I. (c) Austerdalsbreen ice thickness $h(T)$ at the midpoint of the ablation season. Solid curve: numerical solution with 3 months ablation season. Broken curve: Nye (1958) with instantaneous ablation. origin $x=0$ for Odinsbreen ice fall and used Equation (6) to predict the wave pattern at Austerdalsbreen (Fig. 2c). The annual mass balance $b(x)$ and the surface velocity $U(x)$ shown in Figure 2a are redrawn from Nye (1958).

The agreement was good between the observed and predicted wavelength and phase. The theory does not attempt to predict the decay of the waves. The sharpness of the troughs resulted from the unrealistic assumption in Equation (4); the ablation season at Austerdalsbreen actually lasts about 3 months (Nye, 1958).

Wave ogives have been reported in accumulation areas (Atherton, 1963; Post and LaChapelle, 1971, p. 57). Although Nye formulated the theory in terms of instantaneous ablation, the same combination of seasonal mass balance and plastic deformation can produce waves above the firn line.

The ablation-plastic deformation mechanism is capable of producing very large waves at ice falls anywhere on a glacier. The question that arises (e.g. Post and LaChapelle, 1971, p. 57) is: why are large ogives not present below many active ice falls?

\section{WAVE-OGIVE SOLUTION USING METHOD OF CHARACTERISTICS}

The continuity Equation (2) with steady velocity $U(x)$ can be solved in a more general form that includes the wave ogives caused by the mechanism Nye described, and explains the absence of waves below many ice falls.

Multiplying the continuity Equation (2) by $U(x)$ and by $W(x)$, and using Equation (1) gives

$$
\partial Q(x, t) / \partial t+U(x) \partial Q(x, t) / \partial x=A(x, t) U(x) W(x)
$$

Now, I change the distance variable $x$ to a new variable $T(x)$, the time required for ice to flow from the origin $(x=0)$ to position $x . T$ and $x$ are related by

$$
\begin{aligned}
& T(x)=\int_{0}^{x} \frac{\mathrm{d} s}{U(s)}, \\
& x(T)=\int_{0}^{T} U(t) \mathrm{d} t .
\end{aligned}
$$

Nye also used this transformation when evaluating Equation (6). $T$ will be treated as the independent space variable with the understanding that for any spatially varying function $f, f(T) \equiv f(x(T))$.

Using the chain rule with Equations (8) gives

$$
U(x) \frac{\partial Q(x, t)}{\partial x}=\frac{\mathrm{d} x}{\mathrm{~d} T} \frac{\partial Q}{\partial x}=\frac{\partial Q(T, t)}{\partial T}
$$

so that Equation (7) becomes

$$
\frac{\partial Q(T, t)}{\partial t}+\frac{\partial Q(T, t)}{\partial T}=A(T, t) U(T) W(T) .
$$

This equation is readily solved by the method of characteristics (e.g. Whitham, 1974, p. 19) to give

$$
\frac{\mathrm{d} Q}{\mathrm{~d} T}=A(T, t) U(T) W(T)
$$

along the characteristic curves $\mathrm{d} T / \mathrm{d} t=1$, i.e. along $T=t-\phi$ where $\phi$ is an integration constant.

These characteristics (Fig. 3) are the trajectories of the vertical ice columns. Each characteristic is labelled by a unique value of $\phi$, the time when that ice passed the origin.

Equation (11) is a single total derivative in one spatial variable $T$. It resembles Equation (3) used by Nye and is easily integrated to give 


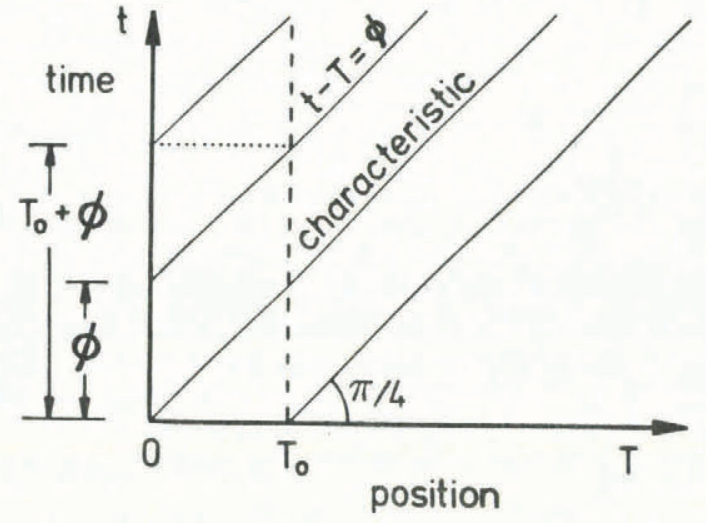

Fig. 3. Characteristics in $(T, t)$ space. $T(x)$ is the time taken by ice to flow from the origin to $x$, so it measures position on the glacier, and $t$ is time. Each characteristic, representing the trajectory of an ice column, is parameterized by $\phi$, the time the ice passed the origin $T=0$.

$$
Q(T, T+\phi)-Q\left(T_{0}, T_{0}+\phi\right)=\int_{T_{0}}^{T} A(s, s+\phi) U(s) W(s) \mathrm{d} s
$$

where $T_{0}$ is a reference position at which the boundary condition is applied.

To represent wave ogives, the solution in Equation (12) must contain terms that correspond to wave forms travelling down the glacier at the speed of the ice, i.e. at 1 year's flow distance per year. This requires the form $Q(t-T)$. Below the ice fall, this propagating solution must also have a spatial periodicity of 1 year's flow distance.

To proceed further, I will assume that the mass balance $A(T, t)$ is separable into the summation

$$
A(T, t)=\sum_{i=1}^{N} \mathrm{x}_{\mathrm{i}}(T) \mathrm{Y}_{\mathrm{i}}(t) .
$$

This form includes, as a special case,

$$
A(T, t)=\chi(T) Y(t)
$$

where the annual cycle $Y(t)$ is weighted by the annual net balance $\chi(T)$ at each position $T$. The mass balance in Equation (4) that Nye used for Austerdalsbreen had this form. Because Equation (12) is linear in the mass balance, the summation in Equation (13) will carry through all the linear operations which follow. To keep the expressions as simple as possible, I can consider the case $N=1$, and drop the subscripts, without loss of generality.

It is possible to introduce travelling wave forms into the solution through propagating mass-balance waves having the form $A(T, t)=b(t-T)$ when $N$ is larger than unity in Equation (13). In fact, the disappearance of the wave ogives can be represented by such terms; zones of excessive ablation rate propagate down the glacier so as to remain on wave crests. I have not included this effect in the examples I show. Any propagating waves formed between $T_{0}$ and $T$ in the examples arise from the ablation-stretching mechanism.

It will be useful, subsequently, to define a function $B(t)$ as an integral of the temporal variation $Y(t)$ of the mass balance

$$
B(t)=\int_{0}^{t} \mathrm{Y}(s) \mathrm{d} s
$$

To simplify the appearance of the equations, I will define a "wave-ogive excitation potential" $\Psi(T)$

$$
\Psi(T)=U(T) W(T) \chi(T)
$$

which comprises the total spatial dependence of the integrand in Equation (12). The gradient of this potential will be the forcing function for wave ogives.

The input flux at the up-stream boundary $T=T_{0}$ is used as a boundary condition. Substituting the mass balance in Equation (14) into the continuity Equation (10) evaluated at the boundary $T_{0}$, gives

$$
\frac{\partial Q\left(T_{0}, t\right)}{\partial t}=\Psi\left(T_{0}\right) Y(t)-\frac{\partial Q\left(T_{0}, t\right)}{\partial \mathrm{T}} .
$$

Integrating this from time zero to time $t=T_{0}+\phi$, i.e. up the vertical boundary line at $T_{0}$ in the $(T, t)$ plane (Fig. 3) using Equation (15), gives

$$
\begin{aligned}
Q\left(T_{0}, T_{0}+\phi\right) & =Q\left(T_{0}, 0\right)+\Psi\left(T_{0}\right) B\left(T_{0}+\phi\right)- \\
& -\int_{0}^{T_{0}+\phi} \frac{\partial Q\left(T_{0}, s\right)}{\partial T} \mathrm{~d} s .
\end{aligned}
$$

This is the input flux at the boundary $T_{0}$ for the characteristic $\phi$. There are three terms. The first is a constant datum flux equal to the flux that crossed the boundary $T_{0}$ at time $t=0$. The second term is the change in flux at the boundary due to the synchronous rise and fall $B(t)$ of the whole surface in response to the seasonal changes. The final term gives the flux changes at the boundary $T_{0}$ due to advection of spatial wave forms through the boundary.

Substituting the mass balance in Equation (14) into the flux solution of Equation (12) using the excitation potential in Equation (16), and recalling that $Y(t)=\mathrm{d} B / \mathrm{d} t$, gives

$$
Q(T, T+\phi)-Q\left(T_{0}, T_{0}+\phi\right)=\int_{T_{0}}^{T} \frac{\mathrm{d} B(s+\phi)}{\mathrm{d} t} \Psi(s) \mathrm{d} s
$$

Integrating by parts on the right-hand side,

$$
\begin{aligned}
& Q(T, T+\phi)-Q\left(T_{0}, T_{0}+\phi\right)= \\
& =\Psi(T) B(T+\phi)-\Psi\left(T_{0}\right) B\left(T_{0}+\phi\right)-\int_{T_{0}}^{T} \frac{\mathrm{d} \Psi(s)}{\mathrm{d} s} B(s+\phi) \mathrm{d} s .
\end{aligned}
$$

After substituting the boundary condition Equation (18), and setting $T+\phi=t$,

$$
\begin{aligned}
Q(T, t) & =Q\left(T_{0}, 0\right)-\int_{0}^{T_{0}+\phi} \frac{\partial Q\left(T_{0}, s\right)}{\partial s} \mathrm{~d} s+\Psi(T) B(t)- \\
& -\int_{T_{0}}^{T} \frac{\mathrm{d} \Psi(s)}{\mathrm{d} s} B(s+[t-T]) \mathrm{d} s .
\end{aligned}
$$

If the summation is carried through from Equation (13),

$$
\begin{aligned}
Q(T, t) & =Q\left(T_{0}, 0\right)-\int_{0}^{T_{0}+\phi} \frac{\partial Q\left(T_{0}, s\right)}{\partial s} \mathrm{~d} s+ \\
& +\sum_{i=1}^{N} \Psi_{\mathrm{i}}(T) B_{\mathrm{i}}(t)+\sum_{i=1}^{N} \int_{T_{0}}^{T_{\mathrm{d} \Psi_{\mathrm{i}}(s)}} B_{\mathrm{i}}(s+[t-T]) \mathrm{d} s .
\end{aligned}
$$

To find the waves in the ice-thickness profile $h(T, t)$, divide through by $U(x(T)) W(x(T))$. To see the waves as a function of distance $x$ rather than the travel time $T$, stretch the $T$ 
axis by the inverse transformation in Equation (8). Equation (22) is the solution for the flux at all times $t$ and positions $T>T_{0}$ with the assumptions:

(1) velocity is steady everywhere, and

(2) mass balance is separable as in Equation (13).

The first three terms in Equation (21) were discussed above. The final term, defined as $P\left(T_{0} T,[t-T]\right)$, yields the wave ogives. The dependence on $[t-T]$ indicates that this term contains a disturbance propagating in the positive $x$ direction at the same speed as the ice.

To represent wave ogives, it must also be an ARS. Because the seasonal balance variation $Y(t)$ has a period of 1 year, so does its integral $B(t)$ (Equation (15)), provided that the mean of $Y(t)$ is made zero by a suitable choice of the terms in Equation (13); then substituting $B(t)=B(t+1)$ into the propagation term $P$ yields $P\left(T_{0}, T,[t-T]\right)=$ $P\left(T_{0}, T,[t+1-T]\right)$, i.e. the wave form is an ARS. Furthermore, for $T$ in a region below the ice fall where the forcing function $\mathrm{d} \Psi / \mathrm{d} T$ vanishes, $P\left(T_{0}, T+1,[t-\mathrm{T}+1]\right)=$ $P\left(T_{0}, T,[t-T]\right)$, i.e. the propagating disturbance is a wave that repeats with a wavelength of 1 year's flow distance.

\section{LINEAR SYSTEMS FORMULATION FOR OGIVES}

\section{Green's function}

Any incremental step change $\Delta \Psi$ in the excitation potential $\Psi(T)$ at position $T_{1}$, or equivalently, an impulse $\Delta \Psi \delta\left(T-T_{1}\right)$ in the forcing function $\mathrm{d} \Psi / \mathrm{d} T$, generates a set of waves given by

$$
G\left([t-T] ; T_{1}\right)=\Delta \Psi B\left(T_{1}+[t-T]\right) .
$$

The function $B\left(T_{1}+[t-T]\right)$ is the Green's function (e.g. Morse and Feshbach, 1953, p. 791) or impulse solution for wave ogives. The total wave pattern is the Green's function multiplied by the forcing function integrated over the whole up-stream region where the excitation potential varies.

Annual waves are not seen on all glaciers because all the small waves due to gradients in velocity, mass balance, or channel width tend to have differing phase; this makes them interfere destructively. Only on glaciers where the gradients are large and localized, such as in an ice fall, can these waves add together constructively to give observable wave ogives.

\section{Physical interpretation}

Nye (1958) illustrated the wave-generating mechanism by the ARS shown in Figure 4. The ice velocity (Fig. 4a) is doubled to $U_{1}=2 U_{0}$ between B and c. Ice travels this
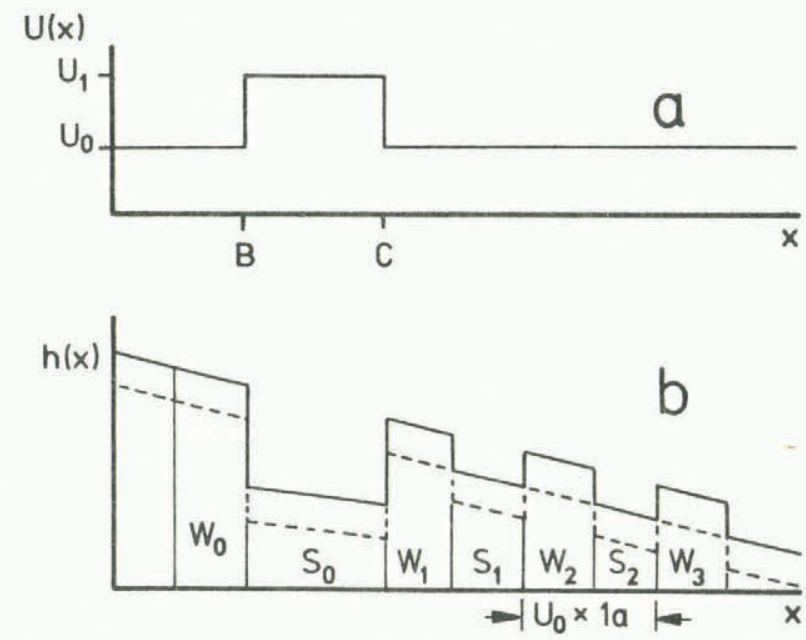

Fig. 4. Double-step ice-fall model. The ice travels the distance $\mathrm{BC}$ in 6 months. The mass balance is constant and is applied instantaneously each year. (a) Ice velocity. (b) Ice thickness: immediately before ablation (solid line): immediately after ablation (dashed line). distance in 6 months. The mass-balance function is spatially constant and is applied instantaneously each year at the same time. The ice thickness (Fig. 4b) immediately before ablation occurs is shown by the solid line. The ice thickness immediately after ablation is shown by the broken line. Before ablation, the volumes of elements $S_{0}$ and $W_{0}$ are equal. $S_{0}$ is on the fast section BC during the summer ablation, while $W_{0}$ is not. Ablation removes approximately twice as much mass from the element $S_{0}$ as from the elements $W_{0}$ and $W_{1}$ on either side, because $S_{0}$ has approximately twice as much surface area exposed to ablation. Down-stream, the volumes $S_{j}$ that were in the ice fall in summer are shorter than the elements $W_{j}$, that passed the ice fall in the winter, so the $S_{j}$ volumes form troughs.

However, the result in Equation (23) indicates that there is an even simpler wave-generating model. If the velocity merely increases or decreases, but not both, waves are still generated. This model is shown in Figure 5 for a decreasing velocity step from $U_{0}$ to $U_{1}=U_{0} / 2$, with an instantaneous, spatially constant mass balance. As before, the solid curve in Figure $5 \mathrm{~b}$ is the ice thickness immediately before ablation and the broken curve is immediately after.

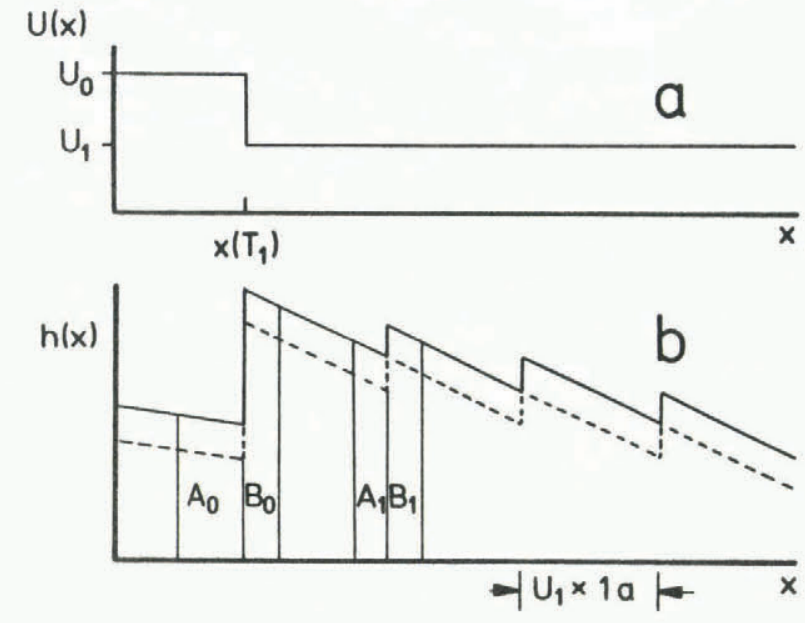

Fig. 5. Single-step model. The constant mass balance is applied instantaneously each year. (a) Ice velocity. (b) Ice thickness: immediately before ablation (solid line); immediately after ablation (dashed line).

In this case, the ablation removes twice the volume from the column $A_{0}$, directly up-glacier from $x\left(T_{1}\right)$, as from the column $B_{0}$ of equal volume directly down-glacier. Later, when both $A_{0}$ and $B_{0}$ have moved down-glacier, and are travelling at the same velocity, $B_{0}$ will stand higher than $A_{0}$. A new discontinuity is generated in this way every year, giving the saw-tooth pattern.

From the definition in Equation (16) of the excitation potential, it is apparent that longitudinal gradients of mass balance and channel width contribute annual waves in the same manner as do velocity gradients. Nye (1958) noted that variations in width and mass balance could generate waves. However, the relative changes in these factors on glaciers are usually less than the relative velocity changes in an ice fall.

These three factors would be expected to influence the wave amplitude on simple physical grounds. If I consider the ice in terms of vertical prisms, the waves arise because the mass balance removes or adds a different amount to prisms immediately above and below the position $x\left(T_{1}\right)$.

As illustrated in Figure $6 \mathrm{a}$, a change of velocity achieves this by stretching the ice prism in the down-stream direction to expose a different surface area. A change in glacier width achieves this by stretching the ice prism laterally (Fig. 6b) to expose a different surface area. A change in mass balance achieves this by removing ice to a different depth in prisms presenting equal surface area (Fig. 

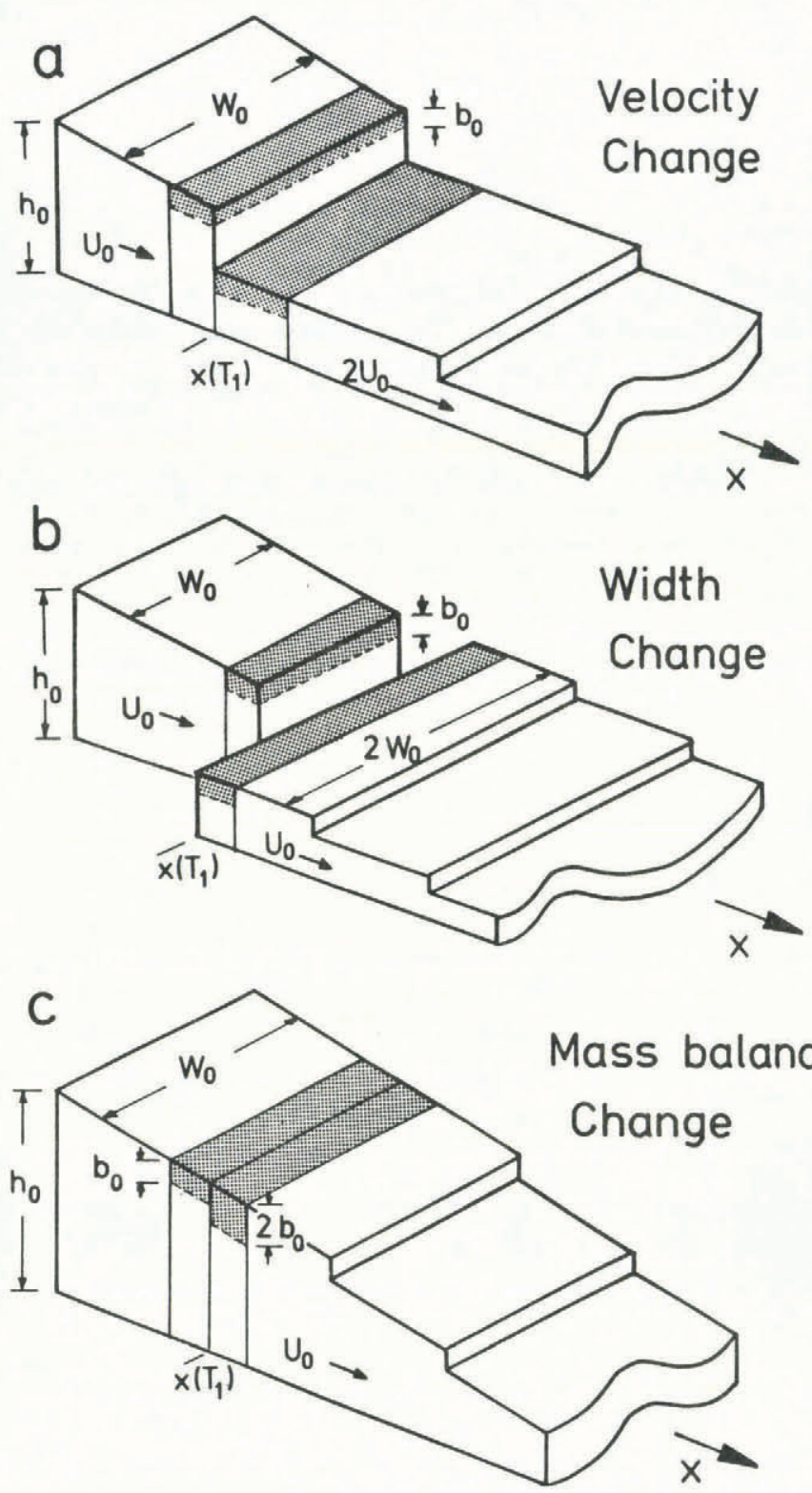

Fig. 6. Three factors generating waves. (a) A change of velocity $U(x)$. (b) A change of width $W(x)$. (c) A change of mass balance $\chi(x)$. The ARS profiles are shown immediately before instantaneous ablation is applied. The shaded volumes indicate the mass about to be ablated from previously equal volumes of ice above and below the transition point $x\left(T_{1}\right)$.

6c). A longer ablation season would generate smoother waves.

\section{Convolution relation}

If I define a reversed cumulative-balance function $B_{\mathrm{r}}(t)=B(-t)$ and if the excitation potential $\Psi(T)$ is constant up-glacier from the boundary $T_{0}$ and down-glacier from the observation point $T$, the ogive term $P$ takes the standard form of a linear convolution of the time-dependent term $B_{\mathrm{r}}$ with the space-dependent term $\mathrm{d} \Psi / \mathrm{d} T$. The variable is $[t-T]=\varnothing$

$$
P(t-T)=\int_{-\infty}^{\infty} \frac{\mathrm{d} \Psi(s)}{\mathrm{d} s} B_{\mathrm{r}}([t-T]-s) \mathrm{d} s .
$$

The theory of convolutions, and algorithms to do convolutions, is widely known. For example, the forcing function $\mathrm{d} \Psi / \mathrm{d} T$ may be treated as a smoothing filter applied to the wave term $B_{r}$.

If the forcing function $d \Psi / d T$ is non-zero down-stream from $T$, the truncated convolution with finite limits must be used for the exact solution. However, if below $T$ the forcing function is small, or is uniform for a large distance, the convolution in Equation (24) is a good approximation. I will show this in the next section. The only significant effect of a small negative velocity gradient is to cause longitudinal compression. This amplifies existing waves expressed in terms of ice thickness and has no effect on waves expressed in terms of ice flux.

\section{IMPLICATIONS}

I will consider two types of driving functions, and use the convolution Equation (24) to illustrate how destructive interference can occur, even on active ice falls, to prevent the formation of observable waves. Combinations of these simple velocity patterns can be applied to any ice fall to get a convenient estimate of the expected ogive-wave amplitude.

\section{Constant potential gradient}

A generalization of the impulsive step change in excitation potential in Equation (23) is a constant potential gradient from $\Psi_{0}$ at $T_{0}$ to $\Psi_{1}$ at $T_{1}$ as shown in Figure 7a. For example, the potential gradient could be due to a velocity gradient.
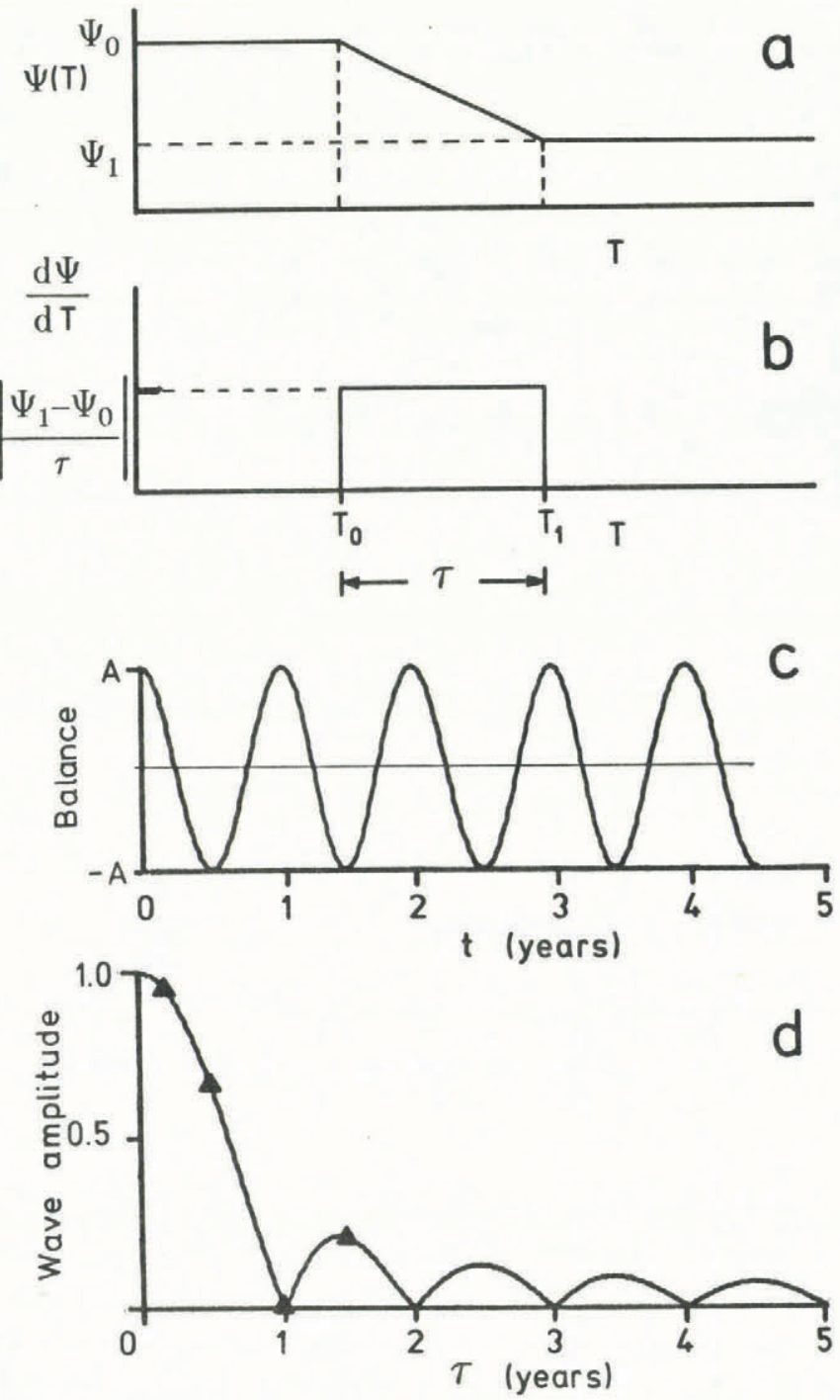

Fig. 7. Amplitude of ogives from a velocity, width, or mass-balance gradient. $T$ is a measure of distance down-glacier, and $t$ is time. (a) Wave-excitation potential. (b) Forcing function. (c) Seasonal mass balance. (d) Normalized crest-to-trough wave amplitude as function of length $\tau$, over which the potential varies. The triangles show the amplitudes of waves in numerical solutions (Fig. 8). 
The forcing function $d \Psi / d T$ in Figure $7 b$ is a "boxcar" function of length $\tau=T_{1}-T_{0}$.

$$
\begin{aligned}
\frac{\mathrm{d} \Psi}{\mathrm{d} T} & =\frac{\Psi_{1}-\Psi_{0}}{T} & & T_{0}<T<T_{1} \\
& =0 & & T<T_{0} \text { or } T>T_{1} .
\end{aligned}
$$

For this forcing function, some general results are immediately apparent. First, the wave amplitude will, in general, tend to decrease as the gradient decreases, i.e. as $\tau$ lengthens, or as $\Psi_{0}$ approaches $\Psi_{1}$. Secondly, because convolution using Equation (25) is (except for a constant factor) just a running average over a distance $\tau$, Equation (24) must be identically zero whenever $\tau$ is an integer and the mass-balance integral $B(t)$ is an annually repeating function with zero mean.

If, for example, the mass balance in Equation (13) is a simple harmonic function

$$
Y(t)=A \cos (2 \pi t)
$$

as shown in Figure $7 c$, then

$$
B_{\mathrm{r}}(t)=-\frac{A}{2 \pi} \sin (2 \pi t)
$$

Performing the convolution in Equation (24) using Equations (25), (27), and the addition formula for cosines, gives

$P(t-T)=-\frac{A\left(\Psi_{1}-\Psi_{0}\right)}{2 \pi}\left[\frac{\sin (\pi \tau)}{\pi \tau}\right] \sin \left(2 \pi[t-T]+\pi\left[T_{1}+T_{0}\right]\right)$.

The final factor is the propagating annual wave train. The crest-to-trough amplitude of this wave train is modulated by

$$
M(\tau)=\left|\frac{A\left(\Psi_{1}-\Psi_{0}\right)}{\pi} \frac{\sin (\pi \tau)}{\pi \tau}\right|
$$

which is shown in Figure 7d. A velocity gradient over an integer number of years generates no waves at all, and the amplitude of the ogive waves falls rapidly with increasing length of the gradient region between zero and 1 year. It remains small for lower gradients, i.e. larger $\tau$. Because differential ablation can destroy wave ogives, waves formed by gradients longer than 6 months may, in most cases, be too small to be observable.

I have used the finite-difference numerical model described by Waddington (unpublished) to solve the continuity Equation (10) for flow past constant potential gradients of four different lengths $\tau$. The terms in the analytical solution in Equation (21) can be identified in these numerical solutions shown in Figure 8. The first term $Q\left(T_{0}, 0\right)=Q_{0}$ is the amplitude at the up-stream boundary $T=T_{0}=0$, as the ice surface passes through its average level in the middle of the accumulation season. The second term is zero, because there are no input wave forms at the boundary $T=0$. The third term is the synchronous rise and fall of the surface with the seasons (clearest in Figure $8 c$ ). The fourth term describes the wave ogives, annually repeating waves propagating at a velocity of unity. The triangular points on Figure 7d are the wave amplitudes from these numerical solutions. Figure 8 illustrates the differences in wave amplitude due to differences in the driving functions.

\section{Double-step ice-fall model}

Nye (1958) illustrated the ablation-stretching mechanism with the model in Figure 4a. The amplitude of the waves is a function of $\tau$, the length of the "ice fall", as shown in Figure 9a. The driving function $d \Psi / d T$ is two Dirac delta functions of opposite polarity (Fig. 9b). Note that if $B_{r}$ is annually repeating, and if $\tau$ is an integer, these two delta functions contribute equal and opposite amounts to the convolution in Equation (24), and no waves are formed.
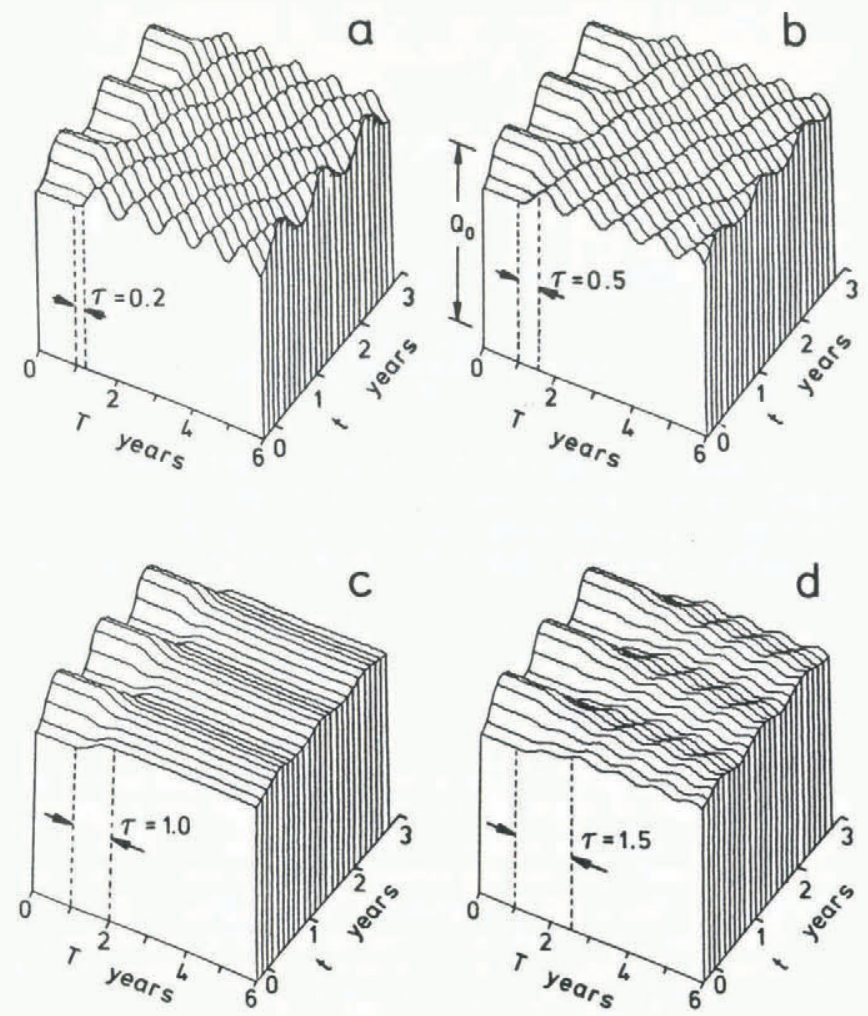

Fig. 8. Flow past a velocity gradient. Numerical solution for ice flux $Q(T, t)$ for various gradient lengths $\tau$. $T$ is a measure of distance down-glacier, and $t$ is time. Ice-flux profiles are shown at intervals of 1.5 months. The velocity and the mass balance have the form in Figure 7. (a) $\tau=0.2$; (b) $\tau=0.5$; (c) $\tau=1.0$; (d) $\tau=1.5$.
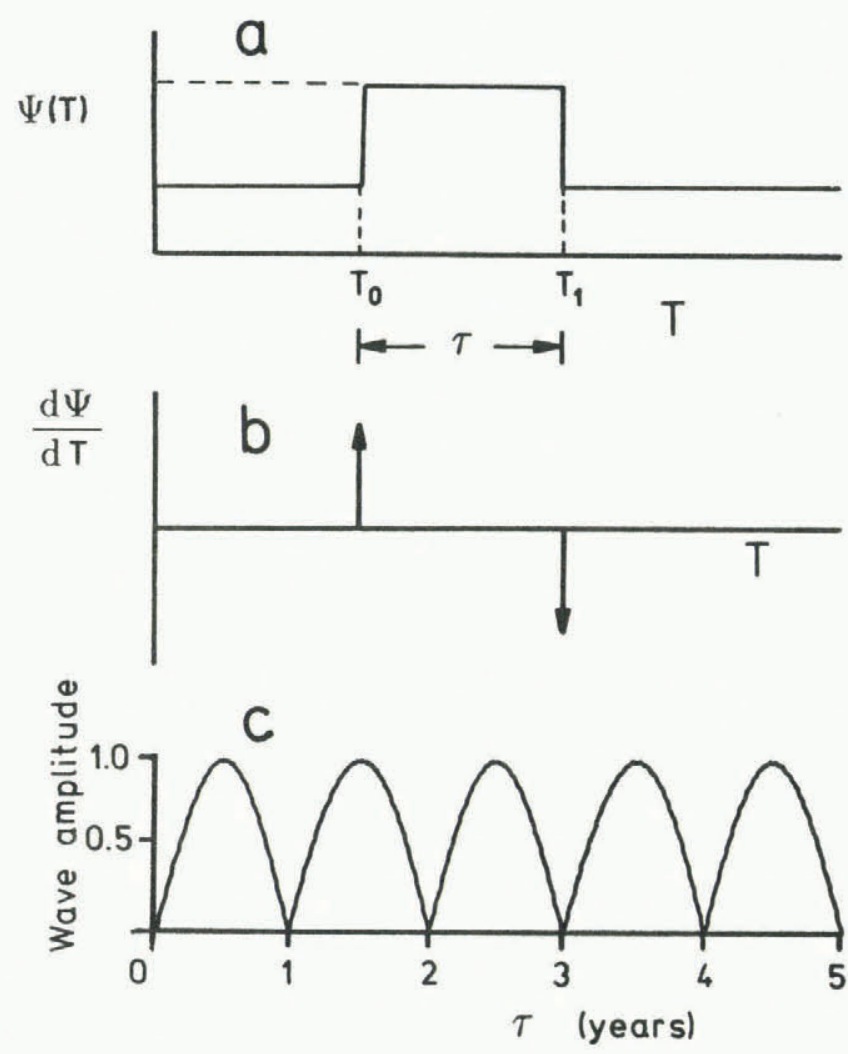

Fig. 9. Double-step ice-fall model. $T$ is a measure of distance down-glacier, and $t$ is time. The mass balance is given in Figure $7 c$. (a) Wave-excitation potential. (b) Forcing function. (c) Normalized crest-to-trough amplitude of waves as a function of ice-fall length $\boldsymbol{\tau}$. 
Using the harmonic mass balance in Equation (26), the convolution in Equation (24) becomes

$$
P(t-T)=-\frac{A\left(\Psi_{1}-\Psi_{0}\right)}{\pi} \sin (\pi T) \sin \left(2 \pi[t-T]+\pi\left[T_{1}+T_{0}\right]\right)
$$

The peak-to-trough amplitude is given by

$$
M(\tau)=\left|\frac{2 A\left(\Psi_{1}-\Psi_{0}\right)}{\pi} \sin (\pi \tau)\right|
$$

This function is shown in Figure 9c. Even when the velocity changes are abrupt, the wave interference from the speed-up phase and from the deceleration phase modulates the ogive amplitude, depending on the length of the ice fall.

\section{AUSTERDALSBREEN}

King and Lewis (1961) attributed the Forbes bands on Austerdalsbreen to seasonal differences in dust accumulation, melting, and snow accumulation in the crevasses formed in the upper part of the Odinsbre ice fall, where the ice undergoes a longitudinal extension. This region is between $x=500 \mathrm{~m}$ and $x=1000 \mathrm{~m}$ in Figure 2. Since wave ogives are often associated with Forbes bands, it is interesting to see which sections of the Odinsbre ice fall are most important for forming the waves.

If I assume that the width variations are unimportant (Nye (1958) also assumed this), then, multiplying the curve $U(x)$ by $b(x)$ (Fig. 2a), and using the transformation in Equation (8), gives the excitation potential $\Psi(T)$ for unit width on Odinsbreen (Fig. 2b). This curve can be approximated by four sections of constant gradient. Table I gives the relative wave-amplitude function $M(\tau)$ for each section. Although Equation (29) is exact only for the mass balance in Equation (26), other annually varying massbalance functions would show similar dependence of wave amplitude on $\tau$. Table I suggests that the largest contribution to the generation of the waves comes from the initial

TABLE I. ODINSBREEN EXCITATION POTENTIAL $\Psi$ APPROXIMATED BY LINEAR SECTIONS. THE END POINTS ARE SHOWN BY ARROWS ON FIGURE $2 \mathrm{~b}$ $W=1 \mathrm{~m}, M(\tau)$ IS GIVEN BY EQUATION (29). $M(0)$ FOR SECTION 1 IS USED TO NORMALIZE ALL SECTIONS

$\begin{array}{cccccc}\text { Section } & T_{0} & T_{1} & \tau & \begin{array}{c}\Psi_{1}-\Psi_{0} \\ \mathrm{~m}^{3} \mathrm{a}^{-2}\end{array} & M(\tau) / M(0) \\ & \mathrm{a} & \mathrm{a} & \mathrm{a} & & \\ 1 & 0.5 & 0.9 & 0.4 & -5500 & 0.76 \\ 2 & 0.9 & 1.6 & 0.7 & 2200 & 0.15 \\ 3 & 1.6 & 2.6 & 1.0 & 1100 & 0.0 \\ 4 & 2.6 & 5.0 & 2.4 & 400 & 0.01\end{array}$

section of the ice fall as the ice accelerates to maximum speed. This is the same section that King and Lewis (1961) identified as the region responsible for the formation of the Forbes bands.

To test this idea, I have used the Odinsbre ice-fall profile (Fig. 2a) to solve the continuity Equation (10) with the numerical model from Waddington (unpublished). The up-stream boundary condition was satisfied by a constant input flux using Nye's (1958) values of ice thickness $(h=13.8 \mathrm{~m})$ and ice velocity $\left(U=1375 \mathrm{~m} \mathrm{a}^{-1}\right)$. (For Nye's model of Austerdalsbreen, the input flux was constant in time because the mass balance at the top of the ice fall was zero.)

Because the finite-difference model cannot accurately represent an instantaneous mass balance of the form in Equation (4), I used a constant ablation rate for 3 months each year. This is a more realistic representation of the Austerdalsbre mass balance (Nye, 1958). Figure 10a shows
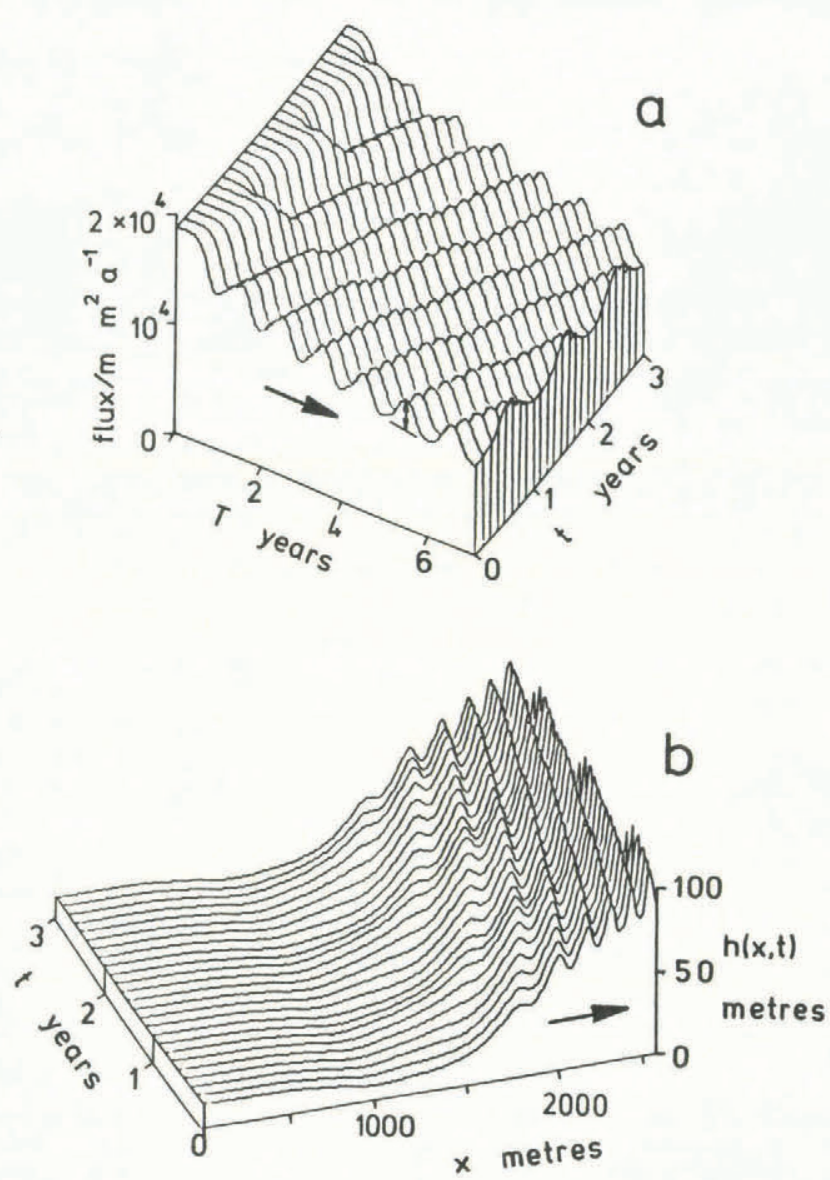

Fig. 10. Austerdalsbreen wave ogives. The numerical solution using the excitation potential in Figure $2 b$, with constant input flux at $T=0$ and $a 3$ month constant ablation season. Profiles at 1.5 month intervals. $T$ is a measure of distance down-glacier and $t$ is time. (a) Ice flux $Q(T, t)$; (b) Ice thickness $h(x, t)$.

the computed ice flux $Q(T, t)$. Figure $10 \mathrm{~b}$ shows the transformation to ice thickness $h(x, t)$. The amplification of the wave height due to compressive flow is apparent. The solid curve in Figure 2c shows the ice-thickness profile $h(T)$ in the middle of the ablation season. For comparison, the broken line is the wave pattern found by Nye using an instantaneous ablation season. The longer ablation season smooths out the sharp troughs on the waves.

To test whether the steep gradient of $\Psi(T)$ in the upper ice fall causes the wave ogives, I then used the numerical model with two modified forcing functions. To generate the annual repeating state in Figure $11 \mathrm{a}$, I brought the ice into the ice fall already travelling rapidly to give constant excitation potential of $-5500 \mathrm{~m}^{3} \mathrm{a}^{-2}$, i.e. on the dotted horizontal curve $\mathbf{A C}$ in Figure $2 \mathrm{~b}$. Then I let the ice slow down following the observed Odinsbre potential curve (CD). The up-stream boundary condition in Equation (18) for this model is time-dependent, because $\Psi(0)$ is no longer zero. The waves generated in this model have only $15-20 \%$ of the amplitude of those in Figure 10a. The prediction in Table I was $15 \%$.

Next, I used the standard Odinsbre excitation potential (solid line BC) up to the peak. Then I let the ice leave the ice fall and travel down Austerdalsbreen without slowing down (dashed horizontal line $\mathrm{CE}$ ). The flux decreases rapidly down-glacier because the ice remains thin, and ablation takes a larger proportion of the mass each year. In fact, the ice thickness becomes zero at $T=4$ year, but $I$ continued the simulation to negative depths to show the waves clearly. The amplitude of the waves (Fig. 11b) is approximately $80 \%$ of the amplitude in Figure 10a. The prediction in Table I was $76 \%$. The rapid velocity increase in the upper region of Odinsbreen causes the waves, and the subsequent 

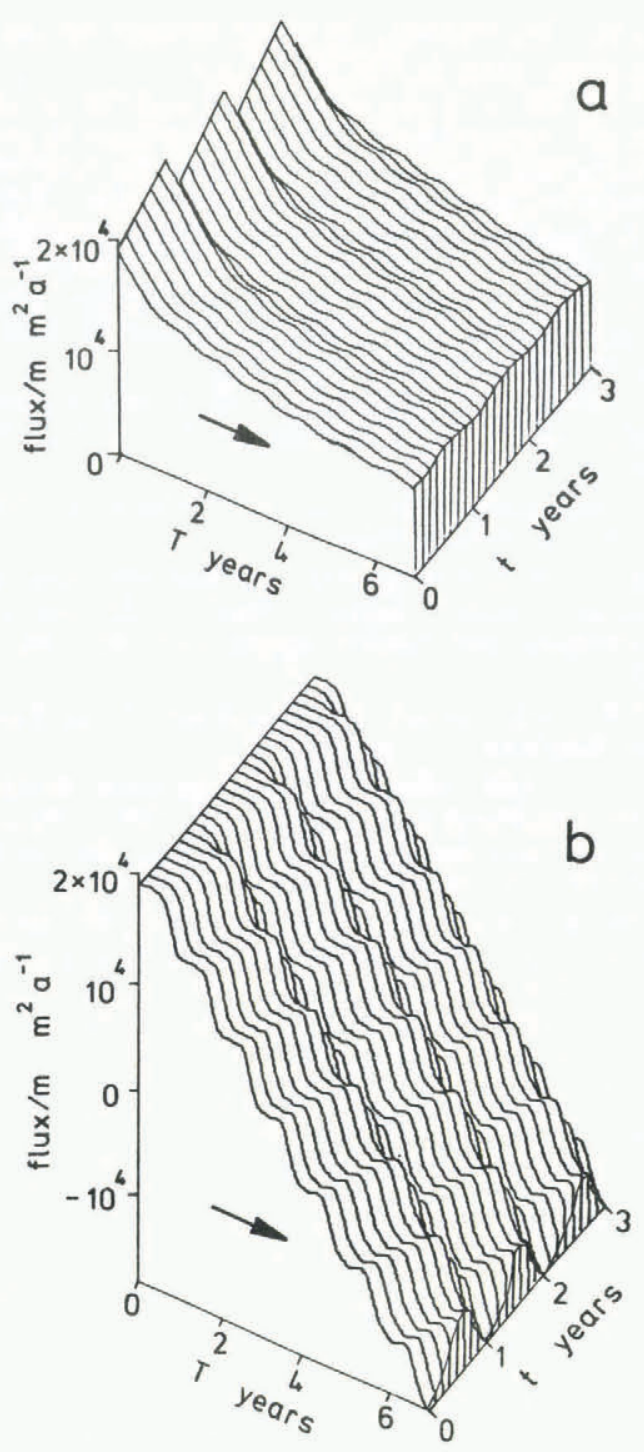

Fig. 11. Isolating the wave-generating region on Odinsbreen ice fall. $T$ is a measure of distance down-glacier, and $t$ is time. (a) Ice follows the excitation potential ACD in Figure $2 b$, i.e. no acceleration as it enters the ice fall. The wave amplitude is small. (b) Ice follows BCE in Figure $2 b$, i.e. no deceleration as it leaves the ice fall. The wave amplitude is comparable to that in Figure 10a. Thus the interval over which the ice speeds up $(x=500-1000 \mathrm{~m})$ is largely responsible for the wave ogives.

deceleration of the ice merely amplifies the wave height by compressive flow. It appears that the rapid extension, that is responsible for the Forbes bands, is also responsible for the formation of wave ogives.

The velocity and ablation data for Séracs du Geant in Vallon (unpublished, p. 52) suggest that the deceleration phase at Mer de Glace also contributes very little to the wave ogives on that glacier.

\section{CONCLUSIONS}

The ablation-plastic stretching mechanism of Nye (1958) has been extended by using the method of characteristics to solve the continuity equation. The total wave-ogive pattern on a glacier can be written as a convolution of a spatial term, the velocity-width-mass-balance gradient (forcing function), with a temporal term, the cumulative mass balance. The convolution describes their interaction.

The forcing function can be viewed as a spatial filter applied to the annually periodic mass balance. Wave ogives appear in the filter output (the glacier-flux profile) only if the filter does not heavily attenuate the annual periodic component. The theory predicts that magnitude and spatial extent of velocity changes in an ice fall modulate the amplitude of the resulting wave ogives. The modulation factor may go to zero.

Since small annual waves may go unnoticed, or be rapidly obliterated by differential ablation, this modulation may explain why some ice falls with rapid ice velocities and large annual balance variations do not generate observable wave ogives by the ablation-stretching mechanism.

Several points of physical interest can also be made:

1. Longitudinal variation of ice velocity, channel width, and mass balance all can generate annual waves in the same way. The waves due to velocity changes are usually the largest.

2. Every incremental change with $x$ of any of these three factors generates a wave train down-glacier. This annually periodic wave train is the Green's function for the total wave pattern.

3. Waves are not observed on all glaciers, because the velocity gradients are small, and waves generated over a large spatial range tend to be out of phase and to interfere destructively.

4. Only large and localized gradients traversed by the ice in 6 months or less can generate waves sufficiently coherent to form large wave ogives.

5. Wave ogives and Forbes bands are of ten found together, because, while the physical processes causing them are different, they both depend on the occurrence of a short zone of rapid ice acceleration, such as the upper stretch of some ice falls.

\section{ACKNOWLEDGEMENTS}

Stimulating discussions with P.K. Fullagar, B.B. Narod, and G.K.C. Clarke, and helpful comments by J.F. Nye clarified several points in this paper. This research was supported by grants from the Natural Sciences and Engineering Research Council of Canada. I am deeply indebted to G.K.C. Clarke without whose dedicated and careful typing, preparation of this paper would not have been possible.

\section{REFERENCES}

Agassiz, L. 1840. Études sur les glaciers. Neuchâtel, author.

Agassiz, L. 1966. Studies on glaciers. London, Dawsons of Pall Mall.

Atherton, D. 1963. Comparisons of ogive systems under various regimes. Journal of Glaciology, Vol. 4, No. 35, p. 547-57.

Elliston, G.R. 1957. A study of the ogives on some of the outlet glaciers of Öræfajökull. Jökull, Ár 7, p. 26-32.

Fisher, J.E. 1947. Forbes' and Alaskan "dirt" bands on glaciers and their origins. American Journal of Science, Vol. 245 , No. 3, p. 137-45.

Fisher, J.E. 1951. The formation of Forbes's bands. Journal of Glaciology, Vol. 1, No. 10, p. 580-81.

Fisher, J.E. 1962. Ogives of the Forbes type on Alpine glaciers and a study of their origin. Journal of Glaciology, Vol. 4, No. 31, p. 53-61.

Forbes, J.D. 1843. Travels through the Alps of Savoy. Edinburgh, A. and C. Black.

Glen, J.W. 1958. The flow law of ice. Union Géodésique et Géophysique Internationale. Association Internationale d'Hydrologie Scientifique. Symposium de Chamonix, 16-24 sept. 1958, p. 171-83. (Publication No. 47 de l'Association Internationale d'Hydrologie Scientifique.)

Godwin, H. 1949. Pollen analysis of glaciers in special relation to the formation of various types of glacier bands. Journal of Glaciology, Vol. 1, No. 6, p. 325-32.

Haefeli, R. 1951[a]. Some observations on glacier flow. Journal of Glaciology, Vol. 1, No. 9, p. 496-500. 
Haefeli, R. 1951[b]. The formation of Forbes's bands. Journal of Glaciology, Vol. 1, No. 10, p. 581-82.

Haefeli, R. 1957. Notes on the formation of ogives as pressure waves. Journal of Glaciology, Vol. 3, No. 21, p. 27-29.

Holdsworth, G. 1969. Structural glaciology of Meserve Glacier. Antarctic Journal of the United States, Vol. 4, No. 4, p. $126-28$.

Hughes, T. 1971. Nonhomogeneous strain studies on Antarctic glaciers. Antarctic Journal of the United States, Vol. 6, No. 4, p. 89-90.

Hughes, T. 1975. A differential ablation-longitudinal compression mechanism for generating wave trains on cold alpine glaciers. [Union Géodésique et Géophysique Internationale. Association Internationale des Sciences Hydrologiques. Commission des Neiges et Glaces.] Symposium. Neiges et glaces. Actes du colloque de Moscou, août 1971, p. 305-17. (IAHS-AISH Publication No. 104.)

Ives, J.D., and King, C.A.M. 1954. Glaciological observations on Morsárjökull, S.W. Vatnajökull. Part I: The ogive banding. Journal of Glaciology, Vol. 2, No. 16, p. 423-28.

King, C.A.M., and Ives, J.D. 1956. Glaciological observations on some of the outlet glaciers of south-west Vatnajökull, Iceland, 1954. Part II: Ogives. Journal of Glaciology, Vol. 2, No. 19, p. 646-51.

King, C.A.M., and Lewis, W.V. 1961. A tentative theory of ogive formation. Journal of Glaciology, Vol. 3, No. 29, p. 913-39.

Langdon, J., and Raymond, C.F. 1978. Numerical calculation of adjustment of a glacier surface to perturbations of ice thickness. Materialy Glyatsiologicheskikh Issledovaniy. Khronika. Obsuzhdeniya, Vyp. 32, p. 233-39.

Leighton, F.B. 1951. Ogives of the East Twin Glacier, Alaska - their nature and origin. Journal of Geology, Vol. 59, No. 6, p. 578-89.

Lick, W. 1970. The propagation of disturbances on glaciers. Journal of Geophysical Research, Vol. 75, No. 12 , p. $2189-97$.

Lliboutry, L. 1957. Banding and volcanic ash on Patagonian glaciers. Journal of Glaciology, Vol. 3, No. 21, p. 20-25.

Lliboutry, L. 1958. Studies of the shrinkage after a sudden advance, blue bands and wave ogives on Glaciar Universidad (central Chilean Andes). Journal of Glaciology, Vol. 3, No. 24, p. 261-70.

Lliboutry, L., and Reynaud, L. 1981. "Global dynamics" of a temperate glacier, Mer de Glace, and past velocities deduced from Forbes's bands. Journal of Glaciology, Vol. 27, No. 96, p. 207-26.

Martin, S. 1978. Analyse et reconstitution de la série des bilans annuels du Glacier de Sarennes, sa relation avec les fluctuations du niveau de trois glaciers du Massif du Mont-Blanc (Bossons, Argentière, Mer de Glace). Zeitschrift für Gletscherkunde und Glazialgeologie, Bd. 13, Ht. $1 / 2,1977$, p. 127-53.
Morse, P.M., and Feshbach, H. 1953. Methods of theoretical physics. New York, McGraw-Hill.

Nye, J.F. 1958. A theory of wave formation in glaciers (Cambridge Austerdalsbre Expedition). [Union Géodésique et Géophysique Internationale. Association Internationale des Sciences Hydrologiques. Commission des Neiges et Glaces.] Symposium. Neiges et glaces. Actes du colloque de Moscou, août 1971, p. 139-54.

Nye, J.F. 1959[a]. A method of determining the strain-rate tensor at the surface of a glacier. Journal of Glaciology, Vol. 3, No. 25, p. 409-19.

Nye, J.F. 1959[b]. The deformation of a glacier below an ice fall. Journal of Glaciology, Vol. 3, No. 25, p. 387-408.

Post, A., and LaChapelle, E.R. 1971. Glacier ice. Toronto, University of Toronto Press.

Reynaud, L. 1979. Reconstruction of past velocities of Mer de Glace using Forbes Bands. Zeitschrift für Gletscherkunde und Glazialgeologie, Bd. 15, Ht. 2, p. 149-63.

Sharp, R.P. 1960. Glaciers. Eugene, Oregon State System of Higher Education.

Sherzer, W.H. 1907. Glaciers of the Canadian Rockies and Selkirks (Smithsonian Expedition of 1904). Washington, DC, Smithsonian Institution. (Smithsonian Contributions to Knowledge, Vol. 34, Article 4.)

Streiff-Becker, R. 1952. Probleme der Firnschichtung. Zeitschrift für Gletscherkunde und Glazialgeologie, Bd. 2, Ht. 1, p. 1-9.

Tyndall, J, 1874. The forms of water. Fourth edition. London, Henry S. King and Co.

Vallon, M. Unpublished. Contribution a l'étude de la Mer de Glace. [Thèse d'État. Publication No. 102 du Laboratoire de Glaciologie du CNRS, Grenoble, 1975.]

Vareschi, V. 1942. Die pollenanalytische Untersuchung der Gletscherbewegung. Veröffentlichungen des Geobotanischen Instituts Rübel in Zürich, Ht. 19.

Waddington, E.D. Unpublished. Accurate modelling of glacier flow. [Ph.D. thesis, University of British Columbia, 1981.]

Washburn, H.B. 1935. Morainic banding of Malaspina Glacier and other Alaskan glaciers. Bulletin of the Geological Society of America, Vol. 46, No. 12, p. 1879-90.

Whitham, G.B. 1974. Linear and nonlinear waves. New York, Wiley-Interscience.

Williams, F.M. 1979. Wave ogives as second-order effects in the creep of large ice masses. Journal of Glaciology, Vol. 24, No. 90, p. 509-10.

Yafeng, S., and Wenying, W. 1980. Research on snow cover in China and the avalanche phenomena of Batura glacier in Pakistan. Journal of Glaciology, Vol. 26, No. 94, p. 25-30. 